\title{
Crescimento, composição mineral e fenóis totais de espécies de Passiflora em função de fontes nitrogenadas
}

\author{
Liliane Barroso de Sousa; Letícia Celia Heitor; Paulo Cesar dos Santos; Jalille Amim Altoé Freitas; \\ Marta Simone Mendonça de Freitas (*); Silvio de Jesus Freitas; Almy Junior Cordeiro de Carvalho \\ Universidade Estadual do Norte Fluminense Darcy Ribeiro (UENF), Av. Alberto Lamego, 2000, Parque Califórnia, \\ 28013-602 Campos dos Goytacazes (RJ), Brasil. \\ (*) Autor correspondente: msimone@uenf.br
}

Recebido: 13/jun./2013; Aceito: 26/jul./2013

\begin{abstract}
Resumo
O trabalho teve como objetivo avaliar a influência de fontes nitrogenadas sobre o crescimento inicial, os teores nutricionais e os fenóis totais contidos nas folhas do ramo primário de três espécies de Passiflora e ainda, os efeitos dessas fontes sobre a composição química do substrato de cultivo. O experimento foi conduzido em delineamento em blocos casualizados em sistema fatorial $4 \times 3$, sendo quatro fontes nitrogenadas (esterco bovino + nitrato de amônio; esterco bovino + sulfato de amônio; esterco bovino + ureia e esterco bovino) e três espécies de Passiflora (Passiflora edulis, Passiflora alata e Passiflora ligularis), com quatro repetições. A espécie P. edulis apresentou maior comprimento, diâmetro e número de brotações do ramo primário em relação às espécies P. alata, e P. ligularis. Os maiores teores de fenóis totais e menores teores de N na massa seca foliar foram observados nas espécies P. alata e P. ligularis adubadas apenas com esterco bovino. Entre as espécies de Passiflora estudadas, a espécie P. edulis apresentou maiores teores foliares de N, P, K e Ca. De acordo com a análise química dos substratos, o tratamento com apenas esterco bovino causou maior pH, maior teor de P e de K, maior soma de bases e maior índice de saturação de bases.
\end{abstract}

Palavras-chave: Passiflora alata, Passiflora edulis, Passiflora ligularis, adubação.

\section{Growth, mineral composition and total phenol of Passiflora species as affected by nitrogen sources}

\begin{abstract}
The study aimed to evaluate the influence of nitrogen sources on the initial growth, the nutritional status and total phenol content in leaves of the primary branch of three species of Passiflora. The effects of nitrogen sources on the chemical composition of the plant substrate were also evaluated. The experiment was carried out in a randomized block design, evaluating four nitrogen sources (manure+ammonium nitrate; manure+ammonium sulfate; manure+urea; and manure) and three species of Passiflora (Passiflora edulis, Passiflora alata and Passiflora ligularis), with four replications. The P. edulis showed greater length, diameter and number of shoots on the primary branch than P. alata and P. ligularis. The highest total phenolic content and lower concentration of $\mathrm{N}$ in leaf dry mass were observed in P. alata and $P$. ligularis fertilized with only manure. Among the Passiflora species studied, P. edulis had the highest concentrations of N, P, K and Ca. According to the chemical analysis of the substrates, the manure treatment caused higher $\mathrm{pH}$, higher content of $\mathrm{P}$ and $\mathrm{K}$, higher sum of bases and higher bases saturation index.
\end{abstract}

Key words: Passiflora alata, Passiflora edulis, Passiflora ligularis, fertilization.

\section{INTRODUÇÃO}

O maracujá é uma fruta de grande importância econômica no Brasil, tanto pelo aproveitamento para consumo in natura quanto processado (MACORIs et al., 2011), além de apresentar potencial para extração de essências aromáticas (Oliverra et al., 2012). Os cultivos comerciais baseiam-se quase que exclusivamente em Passiflora edulis, ocupando cerca de $95 \%$ dos pomares comerciais (MELETTI e BRÜCKNER, 2001). Os demais 5\% encontram-se divididos entre outras passifloras, como a Passiflora alata, Passiflora quadrangularis, Passiflora caerulea e Passiflora laurifolia.

O nitrogênio é um elemento que participa de diversos compostos considerados indispensáveis para o crescimento e desenvolvimento das plantas (Freitas et al., 2011). Para o maracujazeiro amarelo, é um dos nutrientes mais requeridos para esta espécie (Moraes et al., 2011; Santos et al. 2011). Segundo Freitas et al. (2011) a deficiência de nitrogênio em plantas de maracujazeiro-doce, provoca clorose generalizada e queda prematura de folhas, flores 
com coloração vermelho-clara e frutos amarelo claros com aspecto translúcido.

A ureia (45\% de nitrogênio) se destaca entre as fontes de nitrogênio no mercado pela facilidade de acesso, menor custo por unidade de nitrogênio, elevada solubilidade e compatibilidade para a mistura com outros fertilizantes (Yano et al., 2005). Por outro lado, essa fonte é perdida com muita facilidade por volatilização, além de acidificar o substrato de cultivo. Além da ureia, outros adubos também são utilizados como fonte de nitrogênio, como o sulfato de amônio (20\% de nitrogênio) e o nitrato de amônio (33\% de nitrogênio), que contém o nitrogênio na forma amoniacal (Silva et al., 2012).

A prática da adubação exige conhecimentos sobre as características morfofisiológicas da planta, além daquelas relacionadas com a disponibilidade dos nutrientes no solo e com o seu comportamento na planta podendo os nutrientes serem fornecidos por meio da adubação orgânica ou mineral. Em maracujazeiro amarelo, Pires et al. (2009) verificaram que adubos orgânicos proporcionaram produtividade, qualidade dos frutos e teores foliares de $\mathrm{P}$ e Ca semelhantes às plantas submetidas à adubação mineral.

A produção de compostos fenólicos, em muitos casos, está associada com a resposta aos mecanismos de interação da planta com o ambiente, que pode ser desencadeada em condiçôes de estresse. Dentre os fatores de estresse, a nutriçáo mineral é um dos mais importantes, e segundo Freitas et al. (2008) e Leite et al. (2012), a deficiência mineral pode promover maior ou menor produção de compostos fenólicos. Por outro lado, o aumento dos compostos fenólicos em relação à disponibilidade de nutrientes no solo, pode variar entre as espécies de planta e com as diferentes rotas de biossíntese desses compostos (Haukioja et al., 1998).

Informaçôes a respeito do desenvolvimento das espécies $P$. alata e ao $P$. ligularis quando adubadas com diferentes fontes nitrogenadas são ainda desconhecidas, principalmente no que tange ao crescimento, a nutrição mineral e a produção de compostos fenólicos, sendo usualmente utilizados como parâmetro de comparação valores do $P$. edulis para as outras espécies de passiflora.

Nesse sentido, o objetivo deste trabalho foi avaliar o crescimento inicial, os teores nutricionais e a produção de fenóis totais em três espécies de Passiflora submetidas a diferentes fontes nitrogenadas, bem como o efeito das mesmas com relação as características químicas do substrato ao final do experimento.

\section{MATERIAL E MÉTODOS}

O experimento foi conduzido sob delineamento em blocos casualizados (DBC), em esquema fatorial $4 \times 3$, sendo quatro fontes nitrogenadas (esterco bovino + nitrato de amônio; esterco bovino + sulfato de amônio; esterco bovino + ureia e esterco bovino) e três espécies de Passiflora (P. edulis, P. alata e P. ligularis), com quatro repetiçóes.

As sementes de Passiflora foram coletadas de frutos obtidos de lotes comerciais e colocadas para germinar em tubetes de $50 \mathrm{~cm}^{3}$, preenchidos com substrato comercial Plantmax ${ }^{\oplus}$. Quando as plântulas atigiram cinco centímetros de altura, estas foram transplantadas para vasos de $30 \mathrm{dm}^{3}$, preenchidos com uma mistura composta de solo, areia e esterco bovino, na proporção de (3:1:1), cuja analise química foram: $\mathrm{pH}$ em água $=6,9$; matéria orgânica $=25,0 \mathrm{~g} \mathrm{dm}^{-3} ; \mathrm{T}=52,8 \mathrm{mmol}_{\mathrm{c}} \mathrm{dm}^{-3} ; \mathrm{V}=73 \%$; $\mathrm{P}=41,6 \mathrm{mg} \mathrm{dm}{ }^{-3} ; \mathrm{K}^{+}=6,9 \mathrm{mmol}_{\mathrm{c}} \mathrm{dm}^{-3} ; \mathrm{Ca}^{2+}=16,3 \mathrm{mmol} \mathrm{dm}^{-3}$; $\mathrm{Mg}^{2+}=14,6 \mathrm{mmol}_{\mathrm{c}} \mathrm{dm}^{-3} ; \mathrm{Al}^{3+}=0,0 \mathrm{mmol}_{\mathrm{c}} \mathrm{dm}^{-3}$; $\mathrm{SB}=38,0 \mathrm{mmol}_{\mathrm{c}} \mathrm{dm}^{-3} ; \mathrm{Fe}=39,0 \mathrm{mg} \mathrm{dm}^{-3} ; \mathrm{Cu}=0,69 \mathrm{mg} \mathrm{dm}^{-3}$; $\mathrm{Zn}=6,06 \mathrm{mg} \mathrm{dm}^{-3} ; \mathrm{Mn}=16,5 \mathrm{mg} \mathrm{dm}^{-3} \mathrm{e} \mathrm{B}=0,28 \mathrm{mg} \mathrm{dm}^{-3}$.

As plantas receberam $15 \mathrm{~g}$ de nitrogênio por vaso, de cada fonte nitrogenada (nitrato de amônio, sulfato de amônio e ureia), sendo a aplicação dividida em duas vezes. A primeira adubação foi realizada aos 30 dias após o tranplantio com $5 \mathrm{~g}$ de nitrogênio por vaso, período em que as plantas encontravam-se com aproximadamente $20 \mathrm{~cm}$ de altura. Após um intervalo de 35 dias, realizou-se a segunda adubação, na qual foi aplicado $10 \mathrm{~g}$ de nitrogênio por vaso.

As avaliaçóes das plantas foram efetuadas aos $50,70 \mathrm{e}$ 100 dias após o transplantio. As variáveis avaliadas foram: comprimento do ramo primário (determinado a partir da superfície do substrato até a gema apical por meio de trena milimetrada), diâmetro do caule (determinado a $20 \mathrm{~cm}$ de altura do substrato por meio de paquímetro digital), número de folhas e número de brotaçôes. Após a contagem do número de brotaçôes estas foram destacadas do ramo principal.

Aos 77 dias após o transplantio foram coletadas as $4^{\circ}, 5^{\circ}$, $6^{\circ}$ e $7^{\circ}$ folhas a partir do ápice do ramo para avaliação do estado nutricional das plantas e a extração dos fenóis totais. As amostras foliares foram secas em estufa de ventilaçáo forçada de ar à temperatura de $45^{\circ} \mathrm{C}$ até peso constante. Em seguida, foram determinados os teores de nitrogênio $(\mathrm{N})$, fósforo $(\mathrm{P})$, potássio $(\mathrm{K})$, cálcio $(\mathrm{Ca})$, magnésio $(\mathrm{Mg})$ e enxofre $(S)$ e ainda, os teores de fenóis totais.

Para a determinaçáo do teor de N, P e K o material vegetal foi submetido à oxidação pela digestão sulfúrica. $\mathrm{O}$ $\mathrm{N}$ foi determinado pelo método de Nessler, o P pelo método colorimétrico do molibdato e o K por espectrofotometria de emissão de chama. Para a determinação dos teores de $\mathrm{Ca}, \mathrm{Mg}$ e $S$ o material vegetal foi submetido à digestáo nítrico-perclórica. $\mathrm{O} \mathrm{Ca}$ e $\mathrm{Mg}$ foram quantificados por espectrofotometria de absorção atômica e o $S$ por turbidimetria com cloreto de bário. A extração dos fenóis totais foi realizada pelo método de Folin-Dennis, utilizando o ácido tânico como padrão (ANDERSOn e Ingram, 1993).

Aos 100 dias após transplantio, as plantas foram coletadas e avaliadas quanto: a área foliar total (determinada mediante medidor de área foliar modelo LI - 3100 LICOR); massa seca das folhas, massa seca total da parte aérea (caule e folhas) e 
massa seca das raízes (após secagem em estufa de circulação forçada de ar a $70^{\circ} \mathrm{C}$ até peso constate). Neste momento, também foram avaliadas as caracteristicas químicas do substrato de cultivo, como $\mathrm{pH}$ em água, enxofre $\left(\mathrm{S}_{-} \mathrm{SO}_{4}\right)$, fósforo $(\mathrm{P})$, potássio $(\mathrm{K})$, capacidade de troca catiônica (CTC), soma de bases (SB) e saturação por bases $(\mathrm{V})$.

Os dados foram submetidos a análises de variância pelo teste $\mathrm{F}$ e as médias comparadas pelo teste de Tukey. Ambos os testes foram conduzidos à $5 \%$ de significância.

\section{RESULTADOS E DISCUSSÃO}

Aos 70 dias após o transplantio, foi verificada diferenças entre as espécies de Passiflora quanto ao comprimento do ramo primário das plantas, de modo que as espécies $P$. edulis e
P. alata foram iguais quanto a essa característica (Figura 1a). Por outro lado, aos 100 dias após o transplantio, a espécie P. edulis apresentou maior comprimento médio do ramo primário $(506,3 \mathrm{~cm})$ em relação as demais espécies (Figura 1a).

Observa- se na Figura 1b que aos 50 e 70 dias após o transplantio as espécies não apresentaram diferença estatística para o diâmetro do caule. Já aos 100 dias após o transplantio, a espécie $P$. edulis apresentou maior diâmetro em relação as demais espécies (7,54 mm). SANTos et al. (2011) avaliando a influência de fontes nitrogenadas sobre o desenvolvimento da espécie $P$. edulis, encontraram média de $5,57 \mathrm{~mm}$ para o diâmetro do caule, aos 127 dias após a semeadura. VITORAZI FilHo et al. (2012) produzindo mudas de $P$. alata inoculadas com o fungo micorrízico Gigaspora margarita verificaram diâmetro de 3,8 mm aos 90 dias após o transplantio.

Com relação ao número de folhas do ramo primário, as diferenças entre as espécies de Passiflora para essa característica (a)

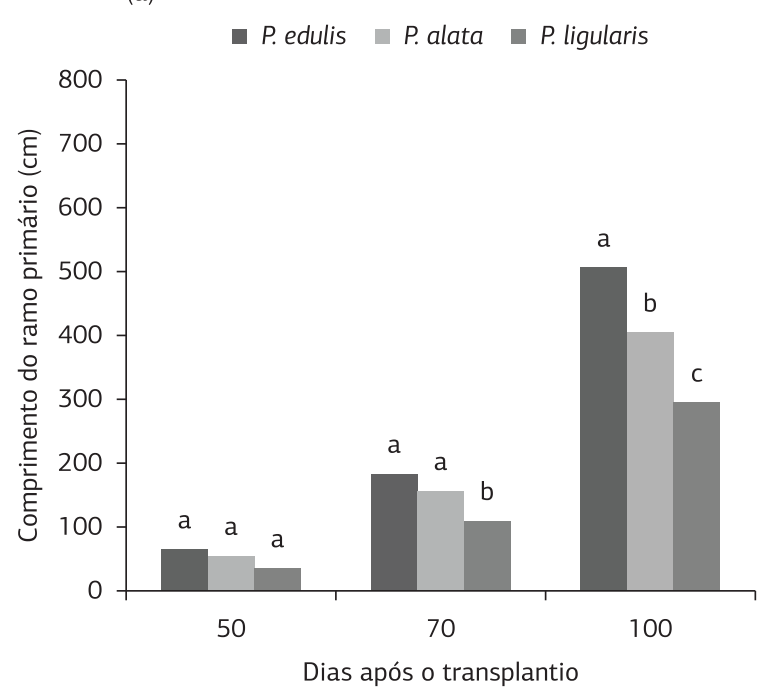

(c)

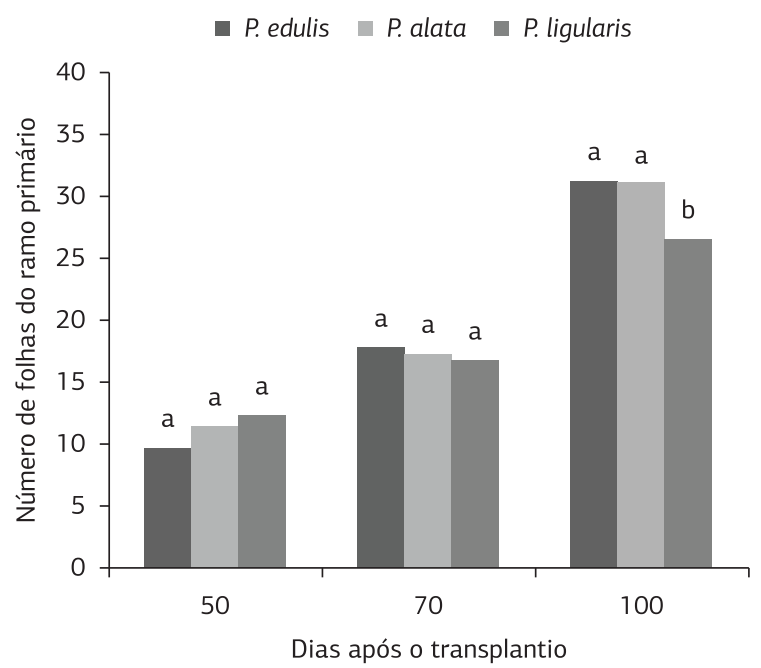

(b)

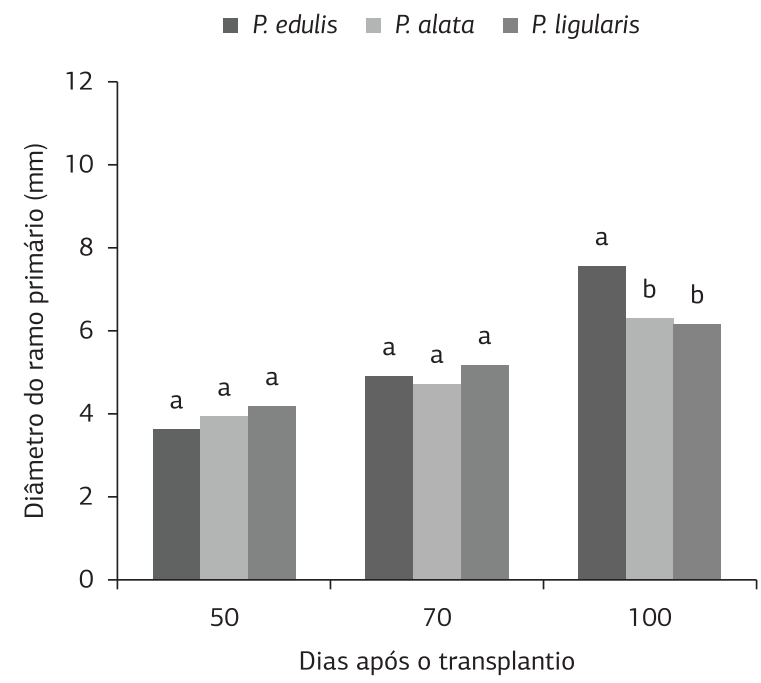

(d)

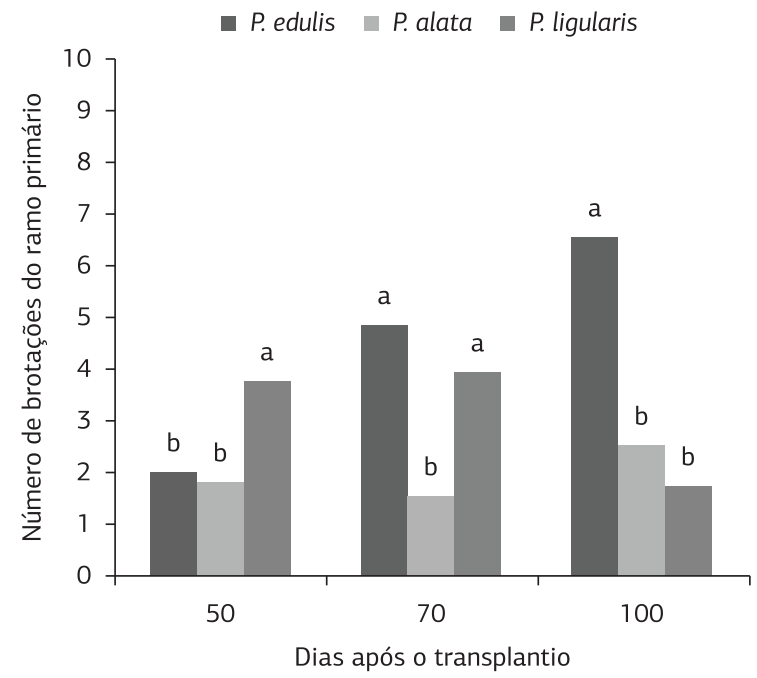

Figura 1. Comprimento do ramo primário (a), diâmetro do ramo primário (b), número de folhas do ramo primário (c) e número de brotaçóes do ramo primário (d) de três espécies de Passiflora em função dos dias após o transplantio em vasos. Médias seguidas pela mesma letra minúscula não diferem entre si pelo teste de Tukey conduzido à $5 \%$ de significância. 
foram verificadas aos 100 dias após o transplantio, sendo de 31,2 e 31,5 para as espécies $P$. edulis e $P$. alata, respectivamente (Figura 1c). Santos et al. (2011) observaram que e aos 127 dias após a semeadura, a espécie $P$. edulis obteve média de 23,92 folhas no ramo primário.

Quanto ao número de brotaçóes emitidas do ramo primário, à espécie P. ligularis obteve média de 3,75 brotos aos 50 dias após o transplantio, sendo superior às demais espécies (Figura 1d). Já aos 70 dias observou-se que a $P$. edulis obteve aumento considerável (média de 4,86 brotos), igualando-se estatisticamente a P. ligularis (Figura 1d). Aos 100 dias após o transplantio, a P. ligularis apresentou menor emissão de brotos (média de 1,74 brotos) não diferindo da espécie $P$. alata, enquanto que a espécie $P$. edulis continuou a apresentar maior média com relação às demais espécies (Figura 1d).

As fontes nitrogenadas fornecidas às plantas não proporcionaram incrementos para as características relacionadas ao comprimento do ramo primário, ao diâmetro do ramo primário e ao número de brotaçôes do ramo primário para as três espécies de Passiflora (Tabela 1).

As espécies $P$. alata e $P$. ligularis apresentaram os maiores teores de fenóis totais (Tabela 2) e concomitantemente os menores teores de $\mathrm{N}$ na massa seca foliar, quando adubadas apenas com esterco bovino (Tabela 3). Teores adequados de nutrientes nas espécies $P$. alata e $P$. ligularis ainda não foram descritos na literatura, sendo comumente utilizados os valores descritos para a espécie $P$. edulis. Segundo Carvalho et al. (2002), a faixa de teores foliares de $\mathrm{N}$ relacionada a maior produtividade para a espécie $P$. edulis é de 40,8 a $58,1 \mathrm{~g} \mathrm{~kg}^{-1}$. Dessa forma, verifica-se que as espécies $P$. alata e $P$. ligularis poderiam estar deficientes neste nutriente.

$\mathrm{O} N$ é o elemento que participa da síntese de aminoácidos e de outros compostos nitrogenados. Plantas deficientes em $\mathrm{N}$ apresentam um desenvolvimento lento (Freitas et al., 2011) e acúmulo de carboidratos, sendo desviados para a síntese de metabólitos secundários (Freitas et al., 2008), como na síntese dos compostos fenólicos (Goвbо-Neto e LOPES, 2007).

Freitas et al. (2008) observaram que plantas de $P$. alata deficientes em nitrogênio apresentaram incrementos de $46 \%$ nos teores de vitexina (compostos fenólicos), quando comparada às plantas que receberam soluçáo completa. Embora trabalhando com outra espécie vegetal, Leite et al. (2012) relataram aumento dos flavonoides em mudas de fava d'anta, quando receberam as menores doses de $\mathrm{N}$.

A espécie $P$. edulis apresentou os maiores teores de $\mathrm{N}$ foliar em todas as fontes nitrogenadas estudadas, quando comparada as outras espécies de Passiflora (Tabela 3). Resultados semelhantes foram encontrados por SANTOS et al. (2011), em que os teores de nitrogênio foliar na espécie P. edulis, variaram de 45,6 a 55,2 $\mathrm{g} \mathrm{kg}^{-1}$, aos 82 dias após a semeadura.
Tabela 1. Comprimento do ramo primário, diâmetro do ramo primário e número de folhas do ramo primário de espécies de Passiflora em função das quatro fontes nitrogenadas

\begin{tabular}{|lccc|} 
Fontes nitrogenadas & $\begin{array}{c}\text { Comprimento } \\
(\mathbf{c m})\end{array}$ & $\begin{array}{c}\text { Diâmetro } \\
(\mathbf{m m})\end{array}$ & $\begin{array}{c}\text { Número de } \\
\text { brotações }\end{array}$ \\
\hline EB* + Nitrato de amônio & $193,6 \mathrm{a}$ & $5,01 \mathrm{a}$ & $3,41 \mathrm{a}$ \\
\hline EB + Sulfato de amônio & $196,0 \mathrm{a}$ & $5,00 \mathrm{a}$ & $3,25 \mathrm{a}$ \\
\hline EB + Ureia & $198,1 \mathrm{a}$ & $5,12 \mathrm{a}$ & $2,80 \mathrm{a}$ \\
\hline EB & $216,8 \mathrm{a}$ & $5,56 \mathrm{a}$ & $3,31 \mathrm{a}$ \\
\hline Média & 201,2 & 5,17 & 3,19 \\
\hline CV (\%) & 22,3 & 19,1 & 50,2 \\
\hline
\end{tabular}

*EB=Esterco bovino. Médias seguidas de pela mesma letra minúscula na coluna năo diferem entre si pelo teste de Tukey conduzido à $5 \%$ de significância

Tabela 2. Teores de fenóis totais (\%) nas folhas de três espécies de Passiflora em função de quatro fontes nitrogenadas

\begin{tabular}{|llllll}
\multicolumn{1}{c}{ Fontes nitrogenadas } & \multicolumn{4}{c}{ Espécies de Passiflora } & Média \\
& P. edulis & P. alata & P. ligularis & \\
\hline EB* + Nitrato de amônio & $1,47 \mathrm{Ab}$ & $1,03 \mathrm{Bb}$ & $1,37 \mathrm{Ab}$ & 1,29 \\
\hline EB + Sulfato de amônio & $1,80 \mathrm{Aa}$ & $1,28 \mathrm{Bb}$ & $1,34 \mathrm{Bb}$ & 1,48 \\
\hline EB + Ureia & $1,41 \mathrm{Ab}$ & $1,17 \mathrm{Ab}$ & $1,16 \mathrm{Ab}$ & 1,25 \\
\hline EB & $1,55 \mathrm{Bab}$ & $2,27 \mathrm{Aa}$ & $2,35 \mathrm{Aa}$ & 2,06 \\
\hline Média & 1,56 & 1,44 & 1,56 & 1,52 \\
\hline CV (\%) & & & & 5,86 \\
\hline
\end{tabular}

*EB=Esterco bovino. Médias seguidas de mesma letra maiúscula nas linhas e minúscula nas colunas năo diferem entre si pelo teste de Tukey conduzido à $5 \%$ de significância

A espécie $P$. alata, apresentou o menor teor de $\mathrm{P}$ $\left(1,69 \mathrm{~g} \mathrm{~kg}^{-1}\right)$ na massa seca foliar, quando adubada com esterco bovino acrescido de ureia (Tabela 3), porém este não foi suficiente para desenvolver deficiência nutricional nas plantas (Freitas et al., 2011) e proporcionar incrementos nos fenóis totais (Tabela 2). As plantas deficientes em fósforo tendem a acumular carboidratos, resultando em desvio de rota para a formação do ácido chiquímico, produzindo ao final do metabolismo as antocianinas, que pertencem à classe dos flavonoides (Mann, 2001). Em P. alata, Freitas et al. (2008) verificaram incrementos de $16 \%$ nos teores de vitexina em plantas cultivadas com omissão de fósforo.

Entre as espécies de Passiflora, a P. edulis apresentou o maior teor de $P$ foliar $\left(2,94 \mathrm{~g} \mathrm{~kg}^{-1}\right)$ quando foi submetida à adubação com esterco bovino acrescido de sulfato de amônio (Tabela 3). Carvalho et al. (2002) definiram que os teores ideais de fósforo para a espécie $P$. edulis encontra-se na faixa de 2,31 a 3,85 $\mathrm{g} \mathrm{kg}^{-1}$. MoraEs et al. (2011) obteve para o P. edulis aos 145 dias após o transplantio, no campo, teores variando de 2,14 a 3,01 $\mathrm{g} \mathrm{kg}^{-1}$. Nesse sentido, verifica-se que o teor de $\mathrm{P}$ obtido neste experimento para esta espécie está adequado. Por outro lado, as fontes nitrogenadas não promoveram diferença estatística no teor de $\mathrm{P}$ foliar da espécie P. ligularis.

$\mathrm{Na}$ espécie $P$. edulis, o menor teor de Ca foliar $\left(11,3 \mathrm{~g} \mathrm{~kg}^{-1}\right)$ foi obtido quando as plantas receberam adubaçáo com esterco acrescido de sulfato de amônio, e maior teor de Ca foliar $\left(21,8 \mathrm{~g} \mathrm{~kg}^{-1}\right)$, quando as plantas foram adubadas 
Tabela 3. Teor de nitrogênio, fósforo, cálcio e magnésio $\left(\mathrm{g} \mathrm{kg}^{-1}\right)$ nas folhas de três espécies de Passiflora em função de quatro fontes nitrogenadas

\begin{tabular}{|c|c|c|c|c|c|c|}
\hline \multirow[t]{3}{*}{ Fontes nitrogenadas } & \multicolumn{3}{|c|}{ Nitrogênio } & \multicolumn{3}{|c|}{ Fósforo } \\
\hline & \multicolumn{3}{|c|}{ Espécies de Passiflora } & \multicolumn{3}{|c|}{ Espécies de Passiflora } \\
\hline & P. edulis & P. alata & P. ligularis & P. edulis & P. alata & P. ligularis \\
\hline $\mathrm{EB}^{*}+$ Nitrato de amônio & $53,7 \mathrm{Aa}$ & 40,2 Bab & $38,3 \mathrm{Ba}$ & $2,86 \mathrm{Aa}$ & $2,71 \mathrm{Aa}$ & $2,35 \mathrm{Ba}$ \\
\hline EB + Sulfato de amônio & $55,3 \mathrm{Aa}$ & $44,0 \mathrm{Ba}$ & $41,3 \mathrm{Ba}$ & 2,94 Aa & 2,54 Bab & $2,28 \mathrm{Ba}$ \\
\hline EB + Ureia & $53,5 \mathrm{Aa}$ & $38,8 \mathrm{Bb}$ & $38,7 \mathrm{Ba}$ & $2,44 \mathrm{Ab}$ & $1,69 \mathrm{Bc}$ & $2,21 \mathrm{Aa}$ \\
\hline EB & $52,9 \mathrm{Aa}$ & $31,9 \mathrm{Bc}$ & $32,0 \mathrm{Bb}$ & 2,63 Aab & $2,32 \mathrm{Ab}$ & $2,35 \mathrm{Aa}$ \\
\hline CV (\%) & & Ć́lrio & & \multicolumn{3}{|c|}{7,6} \\
\hline \multirow[t]{3}{*}{ Fontes nitrogenadas } & \multicolumn{3}{|c|}{ Cálcio } & \multicolumn{3}{|c|}{ Magnésio } \\
\hline & \multicolumn{3}{|c|}{ Espécies de Passiflora } & \multicolumn{3}{|c|}{ Espécies de Passiflora } \\
\hline & P. edulis & P. alata & P. ligularis & P. edulis & P. alata & P. ligularis \\
\hline $\mathrm{EB}^{*}+$ Nitrato de amônio & $15,7 \mathrm{Ab}$ & $11,9 \mathrm{Ba}$ & $12,4 \mathrm{Ba}$ & 5,33 Bab & $5,40 \mathrm{Bab}$ & 6,39 Ab \\
\hline EB + Sulfato de amônio & $11,3 \mathrm{Ac}$ & $8,3 \mathrm{Bb}$ & $9,4 \mathrm{ABb}$ & $5,07 \mathrm{Ab}$ & $4,49 \mathrm{Abc}$ & $5,29 A C$ \\
\hline EB + Ureia & $14,6 \mathrm{Ab}$ & 9,7 Bab & $12,2 \mathrm{Aa}$ & $6,25 \mathrm{Aa}$ & $4,24 \mathrm{Bc}$ & $6,22 \mathrm{Abc}$ \\
\hline EB & $21,8 \mathrm{Aa}$ & $9,1 \mathrm{Cb}$ & 11,9 Bab & 5,97 Bab & $5,58 \mathrm{Ba}$ & $8,05 \mathrm{Aa}$ \\
\hline CV (\%) & & 11,4 & & & 9,5 & \\
\hline
\end{tabular}

*EB=Esterco bovino. Médias seguidas de mesma letra maiúscula nas linhas e minúscula nas colunas nāo diferem entre si pelo teste de Tukey conduzido à $5 \%$ de significância

apenas com o esterco bovino (Tabela 3). Possivelmente o menor teor de $\mathrm{Ca}$ obtido neste trabalho, no tratamento adubaçáo do esterco bovino + sulfato de amônio, pode estar associado pela maior movimentaçáo do Ca nas primeiras camadas de solo, uma vez que o nitrogênio contido no amônio tende a ficar fixado nos coloides do solo e deslocar cátions, como o cálcio, para as camadas mais profundas dificultando com isso sua absorçáo pelas plantas (Coelho e Verlengia, 1973). Em algodoeiro, Foloni e Rosolem (2006) observaram grande lixiviação do Ca e também do $\mathrm{Mg}$ quando estudava a dinâmica de cátions da solução do solo sob diferentes doses de sulfato de amônio.

A adubação com esterco bovino acrescida de nitrato de amônio ou ureia proporcionou maior teor de Ca foliar na espécie $P$. alata. Os teores de Ca foliar verificado para a espécie P. ligularis variaram de 9,4 a 12,4 $\mathrm{g} \mathrm{kg}^{-1}$ (Tabela 3).

Com relação aos teores de $\mathrm{Mg}$ pode-se observar que a espécie $P$. ligularis apresentou maior teor de $\mathrm{Mg}$ foliar quando submetida à adubação com esterco bovino (Tabela 3). Por meio do processo de mineralização e de humificação, o esterco bovino pode liberar bases que se encontravam imobilizadas nos seus tecidos e ainda produzir substâncias húmicas que são capazes de se ligarem a grupamentos como, os carboxílicos (-COOH), os alcoólicos $(-\mathrm{OH})$ e os fenólicos $(-\mathrm{OH})$ do solo proporcionando o aumento nos valores de $\mathrm{pH}$ da solução do mesmo (Novais et al., 2007). Valores de $\mathrm{pH}$ em torno da neutralidade, proporcionam maior solubilidade do nutriente no solo e maior absorção pela planta. Em contrapartida, a acidez está correlacionada aos menores teores de Ca e Mg no solo (BüLL et al., 1997) e consequentemente, menor disponibilidade de incorporação dos cátions pelas plantas. SiLva et al. (2008) estudando a influência do esterco bovino sobre as características químicas de um Latossolo, constataram aumento de $\mathrm{pH}$ na camada superficial e maiores teores de $\mathrm{Mg}$ no solo.
A espécie $P$. edulis apresentou maior teor foliar de $\mathrm{K}$ $\left(32,8 \mathrm{~g} \mathrm{~kg}^{-1}\right)$ em relação às outras espécies de Passiflora (Tabela 4). Em outros trabalhos com a espécie P. edulis, SAntos et al. (2011) e Moraes et al. (2011) obtiveram faixas de K na massa seca foliar de 34,8-37,5 e 33,5-38,7 $\mathrm{g} \mathrm{kg}^{-1}$, respectivamente.

Entre as fontes nitrogenadas estudadas, o esterco bovino acrescido de ureia ou somente a adubaçáo com esterco bovino proporcionaram os menores teores de $\mathrm{K}$ na massa seca foliar das plantas (Tabela 5). O maior teor de potássio na massa seca foliar foi observado no tratamento adubado com esterco + sulfato de amônio (Tabela 5).

Os teores médios de potássio foliar em função das fontes nitrogenadas não contribuíram para produção de fenóis totais (Tabela 2 e 5). Já Gobbo-Neto e Lopes (2007) relataram que variaçóes nos teores de $\mathrm{K}$ foliar podem interferir em uma maior ou menor produção de metabólitos secundários, dependendo da espécie da planta e do tipo de rota envolvido no processo de produçáo do metabólito. GarLet et al. (2007) estudando os efeitos da adubação potássica nos teores de óleo essencial, em plantas de menta, concluíram que houve incrementos significativos nos teores de óleos com o aumento das doses de $\mathrm{K}$, porém, o rendimento por planta foi reduzido. Em maracujazeiro doce deficientes em K, Freitas et al. (2008) observaram teores superiores de vitexina em relaçáo ao tratamento completo.

A espécie $P$. ligularis apresentou o menor teor de $S$ na massa seca foliar (Tabela 4). Entre as fontes nitrogenadas, o esterco bovino acrescido de ureia ou só a adubação com esterco bovino proporcionaram os menores teores de $S$ na massa seca foliar (Tabela 5). Os maiores teores de enxofre na massa seca foliar foi obtido no tratamento adubado com esterco + sulfato de amônio (Tabela 5), provavelmente ocasionado pela presença de $24 \%$ de $S$ na formulação deste adubo. 
Tabela 4. Teor de potássio (K), teor de enxofre (S), área foliar do ramo primário (AF), massa seca foliar do ramo primário (MSF), massa seca da parte aérea do ramo primário (MSPA) e massa seca das raízes do ramo primário (MSR) de três espécies de Passiflora

\begin{tabular}{|cccccccc}
$\begin{array}{c}\text { Espécies de } \\
\text { Passiflora }\end{array}$ & $\begin{array}{c}\mathbf{K} \\
\left(\mathbf{g ~ k g}^{-1}\right)\end{array}$ & $\begin{array}{c}\mathbf{S} \\
\left(\mathbf{g ~ k g}^{-1}\right)\end{array}$ & $\begin{array}{c}\mathbf{A F} \\
\left(\mathbf{c m}^{3}\right)\end{array}$ & $\begin{array}{c}\text { MSF } \\
\mathbf{( g )}\end{array}$ & $\begin{array}{c}\text { MSPA } \\
(\mathbf{g})\end{array}$ & $\begin{array}{c}\text { MSR } \\
(\mathbf{g})\end{array}$ \\
\hline P. edulis & $32,8 \mathrm{a}$ & $4,97 \mathrm{a}$ & $7045 \mathrm{a}$ & $29,6 \mathrm{a}$ & $134,5 \mathrm{a}$ & $12,1 \mathrm{a}$ \\
\hline P. alata & $23,2 \mathrm{c}$ & $5,30 \mathrm{a}$ & $4848 \mathrm{~b}$ & $22,6 \mathrm{~b}$ & $51,3 \mathrm{~b}$ & $5,4 \mathrm{~b}$ \\
\hline P. ligularis & $25,7 \mathrm{~b}$ & $3,23 \mathrm{~b}$ & $3639 \mathrm{c}$ & $13,0 \mathrm{c}$ & $21,7 \mathrm{~b}$ & $4,1 \mathrm{~b}$ \\
\hline Média & 27,2 & 4,50 & 5177 & 21,7 & 69,2 & 7,2 \\
\hline CV (\%) & 7,7 & 16,0 & 21,3 & 22,3 & 54,6 & 27,3 \\
\hline
\end{tabular}

Médias seguidas pela mesma letra minúscula na coluna não diferem entre si pelo teste de Tukey conduzido à $5 \%$ de significância

Tabela 5. Teor de potássio (K), teor de enxofre (S), área foliar do ramo primário (AF), massa seca foliar do ramo primário (MSF), massa seca da parte aérea do ramo primário (MSPA) e massa seca das raízes (MSR) de Passiflora em função de quatro fontes nitrogenadas

\begin{tabular}{|c|c|c|c|c|c|c|}
\hline Fontes nitrogenadas & $\begin{array}{c}\mathrm{K} \\
\left(\mathrm{g} \mathrm{kg}^{-1}\right)\end{array}$ & $\begin{array}{c}\mathbf{S} \\
\left(\mathbf{g ~ k g}^{-1}\right)\end{array}$ & $\begin{array}{c}\mathrm{AF} \\
\left(\mathrm{cm}^{3}\right)\end{array}$ & $\begin{array}{c}\text { MSF } \\
\text { (g) }\end{array}$ & $\begin{array}{l}\text { MSPA } \\
\text { (g) }\end{array}$ & $\begin{array}{c}\text { MSR } \\
\text { (g) }\end{array}$ \\
\hline $\mathrm{EB}^{*}+$ Nitrato de amônio & $27,3 a b$ & $4,45 a b$ & $4796 b$ & $18,6 b$ & $53,0 a b$ & $5,3 c$ \\
\hline EB + Sulfato de amônio & $29,5 \mathrm{a}$ & $5,18 \mathrm{a}$ & $5225 b$ & $23,0 a b$ & $63,6 a b$ & $9,0 \mathrm{a}$ \\
\hline EB + Ureia & $26,0 \mathrm{~b}$ & $4,33 \mathrm{~b}$ & $4720 b$ & $20,2 a b$ & $60,3 \mathrm{~b}$ & $6,1 \mathrm{bc}$ \\
\hline EB & $26,3 b$ & $4,05 \mathrm{~b}$ & $5669 a$ & $24,9 a$ & 99,6 a & $8,3 \mathrm{ab}$ \\
\hline Média & 27,2 & 4,50 & 5177 & 21,7 & 69,2 & 7,2 \\
\hline CV (\%) & 7,7 & 16,0 & 21,3 & 22,3 & 54,6 & 27,3 \\
\hline
\end{tabular}

*EB=Esterco bovino. Médias seguidas pela mesma letra minúscula na coluna não diferem entre si pelo teste de Tukey conduzido à $5 \%$ de significância

Ao final do experimento (100 dias após o transplantio), verificou-se que a espécie $P$. edulis apresentou maior média de área foliar total, massa seca da folha, massa seca total da parte aérea e massa seca das raízes (Tabela 4).

Os maiores valores de área foliar total e massa seca total da parte aérea foram obtidos no tratamento sem adição de fonte nitrogenada mineral (Tabela 5). Contudo, este tratamento não diferiu estatisticamente dos tratamentos contendo nitrato de amônio e sulfato de amônio para a massa seca total da parte aérea (Tabela 5). Na literatura alguns autores consideram que a diminuição na área foliar tem sido considerada um dos efeitos mais significativos da deficiência de nitrogênio, pela queda prematura das folhas (FreItAs et al., 2011). Desta forma, verificou-se que o tratamento sem adição de fonte nitrogenada mineral supriu as exigências requeridas pela planta para sua expansão foliar. Para CRUz et al. (2007), a diminuição da área foliar em função da redução dos níveis de nitrogênio fornecidos a cultura pode estar relacionado à redução do potencial de pressão celular, ao aumento na rigidez da parede celular e/ou à redução da divisão celular.

$\mathrm{O}$ tratamento sem adiçáo de fonte nitrogenada mineral apresentou maior massa seca das folhas do ramo primário, não diferindo dos tratamentos com adição de ureia e sulfato de amônio no substrato (Tabela 5). Foi verificado maior massa seca das raízes nos tratamentos esterco bovino + sulfato de amônio e no tratamento sem adição de fonte nitrogenada no substrato (Tabela 5). Estes resultados corroboram aos de SAntos et al. (2011), que obtiveram a maior massa seca de raiz da espécie $P$. edulis quando mantidas em substrato com esterco bovino como fonte de nitrogênio. Efeito oposto foi verificado por Freitas et al. (2012), que obtiveram incremento em biomassa foliar e expansão da área foliar em plantas de $P$. alata, quando adubadas com nitrogênio, na forma de ureia.

As fontes nitrogenadas proporcionaram mudanças no $\mathrm{pH}$ do substrato, de modo que o tratamento contendo apenas esterco bovino foi o que obteve maior média, o que influenciou na disponibilidade dos elementos como o fósforo e o potássio. Mesmo o tratamento contendo apenas o esterco bovino apresentar maior disponibilidade de P e K no solo (Tabela 6), este não proporcionou maior absorção dos nutrientes pelas espécies de Passiflora (Tabelas 3, 4 e 5).

À maior neutralização no $\mathrm{pH}$ do substrato pela adubação com apenas esterco bovino (Tabela 6) acarretou maior absorção de Ca pela espécie $P$. edulis (Tabela 3), visto que o $\mathrm{pH}$ influenciou na solubilidade deste nutriente no meio de cultivo e favoreceu maior absorção pelas plantas (Novais et al., 2007).

$\mathrm{O}$ teor de enxofre, na forma de sulfato $\left(\mathrm{S}-\mathrm{SO}_{4}\right)$ presente no solo, ao final do experimento, foi influenciado pelas fontes nitrogenadas. $\mathrm{O}$ tratamento com esterco + sulfato de amônio apresentou maior teor de $\mathrm{S}_{-} \mathrm{SO}_{4}$ (Tabela 6). Provavelmente o acúmulo deste elemento no substrato está relacionado ao enxofre contido neste adubo.

As maiores médias de CTC foram encontradas nos tratamentos contendo apenas esterco bovino e com esterco bovino + sulfato de amônio (Tabela 6). O tratamento contendo apenas esterco bovino apresentou maior média de soma de bases trocáveis, não havendo diferença significativa entre os demais tratamentos (Tabela 6). As fontes nitrogenadas influenciaram no índice de saturação de bases, onde o tratamento com apenas esterco bovino apresentou os maiores índices e o tratamento esterco bovino + sulfato de amônio os menores índices de saturação de bases (Tabela 6). 
Tabela 6. Valores médios de potencial hidrogeniônico em água $(\mathrm{pH})$, enxofre $\left(\mathrm{S}_{-} \mathrm{SO}_{4}\right)$, fósforo $(\mathrm{P})$, potássio $(\mathrm{K})$, capacidade de troca catiônica (CTC), soma de bases (SB), saturação por bases (V) no substrato constituído por uma mistura de solo, areia e esterco bovino, na proporção de (3:1:1), adubado com quatro fontes nitrogenadas, após 100 dias de cultivo com espécies de Passiflora

\begin{tabular}{|c|c|c|c|c|c|c|c|}
\hline \multirow[t]{2}{*}{ Fontes nitrogenadas } & \multirow[t]{2}{*}{$\mathrm{pH}$} & \multirow{2}{*}{$\begin{array}{c}\mathrm{S}^{-\mathrm{SO}_{4}} \\
\left(\mathrm{mg} \mathrm{dm}^{-3}\right)\end{array}$} & $\mathbf{P}$ & K & СTC & SB & \multirow{2}{*}{$\begin{array}{c}\text { V } \\
(\%)\end{array}$} \\
\hline & & & \multicolumn{4}{|c|}{$\left(\mathrm{mmol}_{\mathrm{c}} \mathrm{dm}^{-3}\right)$} & \\
\hline $\mathrm{EB}^{*}+$ Nitrato de amônio & $4,96 \mathrm{~b}$ & $30,1 \mathrm{~b}$ & $37,6 \mathrm{~b}$ & $5,1 b$ & $71,2 \mathrm{~b}$ & $41,3 \mathrm{~b}$ & $58,3 \mathrm{bc}$ \\
\hline EB + Sulfato de amônio & $4,26 \mathrm{c}$ & $177,0 \mathrm{a}$ & $39,6 b$ & $4,6 b$ & $84,9 a$ & $44,4 b$ & $48,8 \mathrm{c}$ \\
\hline EB + Ureia & $5,33 \mathrm{~b}$ & $21,8 b$ & $40,3 \mathrm{~b}$ & $5,1 \mathrm{~b}$ & $72,2 \mathrm{~b}$ & $46,4 \mathrm{~b}$ & $63,1 \mathrm{~b}$ \\
\hline EB & $6,05 \mathrm{a}$ & $30,1 \mathrm{~b}$ & $51,7 \mathrm{a}$ & $8,6 \mathrm{a}$ & $82,6 \mathrm{a}$ & $70,5 \mathrm{a}$ & $83,3 \mathrm{a}$ \\
\hline Média & 5,10 & 61,4 & 42,3 & 5,9 & 77,7 & 50,6 & 63,4 \\
\hline $\mathrm{CV}(\%)$ & 6,8 & 32,6 & 20,5 & 24,6 & 13,7 & 23,2 & 13,4 \\
\hline
\end{tabular}

${ }^{*} \mathrm{~EB}=$ Esterco Bovino. Médias seguidas de mesma letra minúscula nas colunas não diferem entre si pelo teste de Tukey conduzido à $5 \%$ de significância

\section{CONCLUSÃO}

A espécie $P$. edulis apresenta maior crescimento em relação às espécies $P$. alata, e $P$. ligularis aos 100 dias após o transplantio independentemente da fonte nitrogenada utilizada. As espécies de $P$. alata e $P$. ligularis apresentam os maiores teores de fenóis totais e os menores teores de $\mathrm{N}$ foliar, quando adubadas apenas com esterco bovino. A espécie $P$. edulis apresenta maiores teores foliares de N, P, K e Ca e a espécie P. ligularis o maior teor de $\mathrm{Mg}$ foliar. $\mathrm{O}$ substrato sem a suplementação com a adubação mineral apresenta maior $\mathrm{pH}$, maior teor de fósforo e potássio, maior soma de bases e maior índice de saturação de bases.

\section{REFERÊNCIAS}

ANDERSON, J.D.; INGRAM, J.S.I. Tropical soil biologya and fertility. A handbook of methods. 2.ed. Walling Ford: CAB International, 1993. 171p.

BÜLL, L.T.; LACERDA, S.; NAKAGAWA, J. Termofosfatos: alteraçóes em propriedades químicas em um latossolo vermelho-escuro e eficiência agronômica. Bragantia, v.56, p.169-179, 1997. http:// dx.doi.org/10.1590/S0006-87051997000100018

CARVALHO, A.J.C.; MONNERAT, P.H.; MARTINS, D.P.; BERNARDO, S.; SILVA, J.A. Teores foliares de nutrientes no maracujazeiro amarelo em função da adubação nitrogenada, irrigação e épocas de amostragem. Scientia Agricola, v.59, p.121-127, 2002. http://dx.doi.org/10.1590/S0103-90162002000100018

COELHO, F.S.; VERLENGIA, F. Fertilidade do solo. 2.ed. Campinas: Instituto Campineiro de Ensino Agrícola, 1973. 384p.

CRUZ, J.L.; PELACANI, C.R.; CARVALHO, J.E.B.; SOUZA FILHO, L.F.S.; QUEIROZ, D.C. Níveis de nitrogênio e a taxa fotossintética do mamoeiro "Golden". Ciência Rural, v.37, p.64-71, 2007. http:// dx.doi.org/10.1590/S0103-84782007000100011

FOLONI, J.S.S.; ROSOLEM, C.A. Efeito da calagem e sulfato de amônio no algodão. I - Transporte de cátions e ânions no solo. Revista Brasileira de Ciência do Solo, v.30, p.425-432, 2006. http://dx.doi. org/10.1590/S0100-06832006000300004
FREITAS, M.S.M.; MONNERAT, P.H.; VIEIRA, I.J.C. Mineral Deficiency in Passiflora alata Curtis: vitexin bioproduction. Journal of Plant Nutrition, v.31, p.1844-1854, 2008. http://dx.doi. org/10.1080/01904160802325552

FREITAS, M.S.M.; MONNERAT, P.H.; CARVALHO, A.J.C.; VASCONCELLOS, M.A.S. Sintomas visuais de deficiência de macronutrientes e boro em maracujazeiro-doce. Revista Brasileira de Fruticultura, v.33, p.1329-1341, 2011. http://dx.doi.org/10.1590/ S0100-29452011000400034

FREITAS, J.C.O.; ALMEIDA, A.F.; LAGO, M.F.; SOUZA, M.M.; SOUZA JÚNIOR, J.O. Características morfofisiológicas de plantas clonais de Passiflora alata crescidas em diferentes doses de nitrogênio e níveis de sombreamento. Revista Brasileira de Fruticultura, v.34, p.859872, 2012. http://dx.doi.org/10.1590/S0100-29452012000300028

GARLET, T.M.B.; SANTOS, O.S.; MEDEIROS, S.L.P.; MARFRON, P.A.; GARCIA, D.C.; BORCIONI, E.; FLEIG, V. Produção e qualidade de óleo essencial de menta em hidroponia com doses de potássio. Ciência Rural, v.37, p.956-962, 2007. http://dx.doi.org/10.1590/ S0103-84782007000400006

GOBBO-NETO, L.B.; LOPES, N.P. Plantas medicinais: fatores de influência no conteúdo de metabólitos secundários. Química Nova, v.30, p.374-381, 2007. http://dx.doi.org/10.1590/S010040422007000200026

HAUKIOJA, E.; OSSIPOV, V.; KORICHEVA, J.; HONKANEN, T.; LARSSON, S.; LEMPA, K. Biosynthetic origin of carbon-based secondary compounds: cause of variable responses of woody plants to fertilization? Chemoecology, v.8, p.133-139, 1998. http://dx.doi. org/10.1007/s000490050018

LEITE, G.L.D.; SILVA, F.W.S.; GUANABENS, R.E.M.; FERNANDES, L.A.; FIGUEIREDO, L.S.; SILVA, L.F. NPK and flavonoids affecting insect populations in Dimorphandra mollis seedlings. Acta Scientiarum Agronomy, v.34, p.17-22, 2012. http:// dx.doi.org/10.4025/actasciagron.v34i1.11233

MANN, J. Secondary metabolism. 2.ed. Oxford: Oxford Science, 2001.374p.

MACORIS, M.S; JANZANTTI, N.S.; GARRUTI, D.S.; MONTEIRO, $M$. Volatile compounds from organic and conventional passion fruit (Passiflora edulis f. var flavicarpa Deg.) pulp. Ciência e Tecnologia de Alimentos, v.31, n.2, p.430-435, 2011. http://dx.doi.org/10.1590/ S0101-20612011000200023 
MELETTI, L.M.M.; BRÜCKENER, C.H. Melhoramento genético. In: BRÜCKENER, C.H., PICANÇO, M.C. (Eds) Maracujá: tecnologia de produção, pós-colheita, agroindústria e mercado. Porto Alegre: Cinco Continentes, 2001. p.345-385.

MORAES, J.C.B.; SALCEDO, I.H.; SOUSA, V.F. Doses de potássio por gotejamento no estado nutricional do maracujazeiro. Revista Brasileira de Engenharia Agrícola e Ambiental, v.15, p.763-770, 2011.

NOVAIS, R.F.; ALVAREZ, V.H.; BARROS, N.F.; FONTES, R.L.F.; CANTARUTTI, R.B.; NEVES, J.C.L. Fertilidade do solo. Viçosa: Sociedade Brasileira de Ciência do Solo, 2007. 1017p.

OLIVEIRA, L.C.; SANTOS, J.A.B.; NARAIN, N.; FONTES, A.S.; CAMPOS, R.S.S.; SOUZA, T.L. Caracterização e extração de compostos voláteis de resíduos do processamento de maracujá (Passiflora edulis Sims f. flavicarpa degener). Ciência Rural, v.42, p.2280-2287, 2012. http://dx.doi.org/10.1590/S0103-84782012005000103

PIRES, A.A.; MONNERAT, P.H.; PINHO, L.G.R.; ZAMPIROLLI, P.D.; ROSA, R. C.C.; MUNIZ, R.A. Efeito da adubação alternativa sobre os componentes de produçáo do maracujazeiro-amarelo. Acta Scientiarum Agronomy, v.31, p.655-660, 2009. http://dx.doi. org/10.4025/actasciagron.v31i4.986

SANTOS, P.C.; LOPES, L.C.; FREITAS, S.J.; SOUSA, L.B.; CARVALHO, A.J.C. Crescimento inicial e teor nutricional do maracujazeiro amarelo submetido à adubaçáo com diferentes fontes nitrogenadas. Revista Brasileira de Fruticultura, v.33, p.722-728, 2011. http://dx.doi.org/10.1590/S0100-29452011000500101

SILVA, J.C.P.M.; MOTTA, A.C.V.; PAULETTI, V.; FAVARETTO, N.; BARCELOS, M.; OLIVEIRA, A.S.; VELOSO, C.M.; COSTA E SILVA, L.F. Esterco líquido de bovinos leiteiros combinado com adubação mineral sobre atributos químicos de um Latossolo Bruno. Revista Brasileira de Ciência do Solo, v.32, p.2563-2572, 2008. http:// dx.doi.org/10.1590/S0100-06832008000600033

SILVA, J.T.A.; PEREIRA, R.D.; RODRIGUES, M.G.V. Adubação da bananeira 'Prata Anâ' com diferentes doses e fontes de nitrogênio. Revista Brasileira de Engenharia Agrícola e Ambiental, v.16, p.13141320, 2012. http://dx.doi.org/10.1590/S1415-43662012001200008

VITORAZI FILHO, J.A.; LIMA, K.B.; FREITAS, M.S.M.; MARTINS, M.A.; OLIVARES, F.L. Crescimento de mudas de maracujazeirodoce inoculadas com fungos micorrízicos arbusculares e bactérias diazotróficas sob diferentes doses de fósforo. Revista Brasileira de Fruticultura, v.34, p.442-450, 2012. http://dx.doi.org/10.1590/ S0100-29452012000200017

YANO, G.T.; TAKAHASHI, H.T.; WATANABE, T.S. Avaliação de fontes de nitrogênio e épocas de aplicação em cobertura para o cultivo do trigo. Semina: Ciências Agrárias, v.26, p.141-148, 2005. 


\section{Bragantia, v.72, n.3, 2013}

Devido a um erro de editoração eletrônica, o artigo "Crescimento, composição mineral e fenóis totais de espécies de Passiflora em função de fontes nitrogenadas" necessita de correção no e-mail do autor correspondente.

Pág.247

Onde se lê:

simone@uenf.br

\section{Leia-se:}

msimone@uenf.br 